\title{
Reduced Estimated Glomerular Filtration Rate Is Associated with Stroke Outcome after Intravenous rt-PA: The Stroke Acute Management with Urgent Risk-Factor Assessment and Improvement (SAMURAI) rt-PA Registry
}

\author{
Masaki Naganuma ${ }^{a}$ Masatoshi Koga ${ }^{a}$ Yoshiaki Shiokawa ${ }^{b}$ Jyoji Nakagawarad \\ Eisuke Furui $^{\mathrm{e}}$ Kazumi Kimura $^{f}$ Hiroshi Yamagami ${ }^{g}$ Yasushi Okadah \\ Yasuhiro Hasegawa ${ }^{i}$ Kazuomi Karioj Satoshi Okudak Kazutoshi Nishiyamac \\ Kazuo Minematsu ${ }^{a}$ Kazunori Toyoda ${ }^{a}$ \\ ${ }^{a}$ Department of Cerebrovascular Medicine, National Cerebral and Cardiovascular Center, Suita, Departments \\ of ${ }^{b}$ Neurosurgery and ${ }^{\mathrm{C}}$ Neurology, Stroke Center, Kyorin University School of Medicine, Mitaka, ${ }^{\mathrm{d}}$ Department \\ of Neurosurgery and Stroke Center, Nakamura Memorial Hospital, Sapporo, ' Department of Stroke Neurology, \\ Kohnan Hospital, Sendai, ${ }^{f}$ Department of Stroke Medicine, Kawasaki Medical School, Kurashiki, ${ }^{9}$ Stroke Center, \\ Kobe City Medical Center General Hospital, Kobe, ${ }^{\mathrm{h}}$ Department of Cerebrovascular Diseases, National Hospital \\ Organization, Kyushu Medical Center, Fukuoka, 'Department of Neurology, St. Marianna University School of \\ Medicine, Kawasaki, ${ }^{j}$ Division of Cardiovascular Medicine, Department of Medicine, Jichi Medical University School \\ of Medicine, Shimotsuke, and kDepartment of Neurology, National Hospital Organization, Nagoya Medical Center, \\ Nagoya, Japan
}

\section{Key Words}

Infarction - Intracerebral hemorrhage - Renal dysfunction • rt-PA - SAMURAI

\begin{abstract}
Background: The aim of this study was to determine whether renal dysfunction affects the outcome of stroke patients treated with recombinant tissue plasminogen activator ( $\mathrm{rt}$ PA). Methods: A retrospective, multicenter, observational study was conducted to identify the effects of underlying risk factors on intravenous rt-PA therapy using $0.6 \mathrm{mg} / \mathrm{kg}$ alteplase in 10 stroke centers in Japan. Consecutive stroke patients with a premorbid modified Rankin Scale (mRS) score $\leq 3$ who received rt-PA were studied. Renal dysfunction was defined as estimated glomerular filtration rate (eGFR) $<60$
\end{abstract}

$\mathrm{ml} / \mathrm{min} / 1.73 \mathrm{~m}^{2}$ on admission. The outcome measures were any intracerebral hemorrhage $(\mathrm{ICH})$ and symptomatic $\mathrm{ICH}$ within the initial $36 \mathrm{~h}$; favorable (mRS 0-1) outcome, poor outcome (mRS 4-6) and mortality at 3 months. Results: Of a total of 578 patients ( 372 men; $64.4 \%, 71.4 \pm 11.7$ years old), renal dysfunction was present in 186 patients (32.2\%). These patients were older and more commonly had hypertension, atrial fibrillation, prior ischemic heart disease and prior use of antithrombotic agents than patients without renal dysfunction. ICH (27.4 vs. $16.6 \%$ ) and symptomatic ICH (8.1 vs. $2.6 \%$ ) was more common in patients with renal dysfunction than in those without. At 3 months, patients with renal dysfunction had higher median mRS scores than those without (3 vs. 2). After multivariate adjustment for established outcome predictors, renal dysfunction was related to any $\mathrm{ICH}$ (odds ratio $1.81,95 \%$ confidence interval $1.16-2.84$ ), symp-

\section{KARGER}

Fax +4161306 1234 E-Mail karger@karger.ch www.karger.com
(C) 2010 S. Karger AG, Basel

1015-9770/11/0312-0123\$38.00/0

Accessible online at:

www.karger.com/ced
Kazunori Toyoda, MD

Department of Cerebrovascular Medicine

National Cerebral and Cardiovascular Center

Fujishirodai 5-7-1, Suita, Osaka 565-8565 (Japan)

Tel. +81 66833 5012, Fax +81 66872 7486, E-Mail toyoda@hsp.ncvc.go.jp 
tomatic ICH $(2.64,1.10-6.56)$, poor outcome $(1.55,1.01-2.38)$, and mortality $(2.94,1.38-6.42)$. Conclusions: Reduced eGFR was associated with early ICH and 3-month unfavorable outcome in stroke patients receiving intravenous rt-PA.

Copyright $\odot 2010$ S. Karger AG, Base

\section{Introduction}

Renal dysfunction is increasingly noted as a risk factor for stroke in the general population $[1,2]$, as well as in high-risk patients having diabetes mellitus [3], essential hypertension [4], and preexisting atherothrombotic disease $[5,6]$. In a large cohort of patients with acute stroke, renal dysfunction was an independent predictor for longterm mortality and poor outcome [7-9].

Though intravenous (IV) thrombolysis is a standard therapy for acute stroke patients, the effect of renal dysfunction on vital and functional outcome measures following therapy is inconclusive. As far as we know, only one study (involving 196 stroke patients) reported that a high admission serum creatinine level was independently predictive of a modified Rankin scale (mRS) score $\geq 3$ at 3 months after IV recombinant tissue plasminogen activator (rt-PA) [10]. This study also reported that an impaired estimated glomerular filtration rate (eGFR), defined as $<90 \mathrm{ml} / \mathrm{min} / 1.73 \mathrm{~m}^{2}$, tended to be associated with symptomatic intracerebral hemorrhage (ICH). Since renal dysfunction appears to be an important predictor for stroke outcome, its significance for rt-PA-treated patients should be ascertained in a larger cohort using a multicenter design.

To identify adequate risk factor control in acute stroke patients treated with thrombolysis, a multicenter study group [Stroke Acute Management with Urgent Risk-Factor Assessment and Improvement (SAMURAI) Study Group] was formed. Here, we determined the association of renal dysfunction based on admission eGFR with stroke outcome after IV rt-PA using the database of this study group.

\section{Patients and Methods}

The SAMURAI rt-PA Registry Trial had a multicenter, hospital-based, retrospective, observational, cohort design [11]. Details of this study have been described previously [11, 12]. In brief, this study involved 600 consecutive patients with acute ischemic stroke receiving IV rt-PA from October 2005 to July 2008. Of these, 22 patients were ineligible for analysis; 17 patients had dependent activity of daily living before onset, corresponding to an $\mathrm{mRS}$ score $\geq 4$, and 5 patients had incomplete 3 -month mRS score data. Thus, the remaining 578 patients were included in the present study. Each local ethics committee approved the research protocol. Each patient received a single IV alteplase dose of $0.6 \mathrm{mg} / \mathrm{kg}$, with $10 \%$ given as a bolus within $3 \mathrm{~h}$ of stroke onset, followed by a continuous IV infusion of the remainder over $1 \mathrm{~h} \mathrm{[13].}$

From the database of the SAMURAI rt-PA registers, the data listed in table 1 were extracted for this study. Neurological deficits were assessed using the National Institutes of Health Stroke Scale (NIHSS) score just before and $24 \mathrm{~h}$ after rt-PA. Ischemic stroke subtype according to the TOAST categories was elucidated based on information of non-contrast computed tomography (CT), diffusion-weighted magnetic resonance imaging (MRI), magnetic resonance angiography, CT angiography, cervical/transcranial ultrasound, transthoracic or transesophageal echocardiography, and 24-hour Holter monitoring in addition to neurological findings [14].

Kidney function was evaluated based on the eGFR using a revised equation for the Japanese population [15]; eGFR (ml/ $\left.\mathrm{min} / 1.73 \mathrm{~m}^{2}\right)=194 \times(\text { serum creatinine })^{-1.094} \times(\text { age })^{-0.287} \times$ 0.739 (for women). To calculate eGFR, admission serum creatinine was used. According to the Kidney Disease Outcomes Quality Initiative guidelines of the National Kidney Foundation [16], renal dysfunction was defined as a reduced eGFR $(<60 \mathrm{ml} /$ $\mathrm{min} / 1.73 \mathrm{~m}^{2}$ ). The stage of renal dysfunction was classified as follows: stage 3 (eGFR $30-59 \mathrm{ml} / \mathrm{min} / 1.73 \mathrm{~m}^{2}$ ), stage $4(15-29 \mathrm{ml} /$ $\left.\mathrm{min} / 1.73 \mathrm{~m}^{2}\right)$, and stage $5\left(<15 \mathrm{ml} / \mathrm{min} / 1.73 \mathrm{~m}^{2}\right.$ or dialysis).

The major outcome measures were: any ICH defined as CT or MRI evidence of new ICH within the initial $36 \mathrm{~h}$; symptomatic ICH with neurological deterioration corresponding to an increase of $\geq 1$ point from the baseline NIHSS score (Cochrane/ National Institute of Neurological Disorders and Stroke definition); favorable and poor outcome at 3 months, and mortality at 3 months. To assess favorable and poor outcome, definitions in the subanalyses of the National Institute of Neurological Disorders and Stroke rt-PA Trial (an mRS of $0-1$ and 4-6, respectively) were used [17-20].

\section{Statistical Analysis}

Statistical test results were considered significant if $\mathrm{p}<0.05$. All analyses were performed using JMP statistical software (version 7.0.1; SAS Institute, Cary, N.C., USA). Baseline clinical characteristics and stroke features were compared using Student's unpaired $t$ test for parametric continuous variables, Mann-Whitney's U test for nonparametric variables, and Fisher's exact test and the $\chi^{2}$ test for categorical variables. To identify independent predictors of ICH within $36 \mathrm{~h}$ and stroke outcome at 3 months, multivariate logistic regression analysis was performed. For each outcome, sex, age, and renal dysfunction were initially entered, and the other variables listed in table 1 were chosen by a backward selection procedure using $\mathrm{p}>0.10$ in the likelihood ratio test for exclusion.

\section{Results}

A total of 578 patients ( 372 men, $71.4 \pm 11.7$ years old) were studied. Of these, $186(32.2 \%)$ patients had renal dysfunction with eGFR $<60 \mathrm{ml} / \mathrm{min} / 1.73 \mathrm{~m}^{2} ; 163$ (28.2\%) 
Table 1. Baseline clinical characteristics

\begin{tabular}{|c|c|c|c|}
\hline $\begin{array}{l}\text { Baseline } \\
\text { characteristics }\end{array}$ & $\begin{array}{l}\text { Renal dysfunction } \\
(\mathrm{eGFR}<60 \mathrm{ml} / \mathrm{min} / \\
\left.1.73 \mathrm{~m}^{2}\right)(\mathrm{n}=186)\end{array}$ & $\begin{array}{l}\text { No renal dysfunction } \\
(\mathrm{eGFR} \geq 60 \mathrm{ml} / \mathrm{min} / \\
\left.1.73 \mathrm{~m}^{2}\right)(\mathrm{n}=392)\end{array}$ & $\mathrm{p}$ value \\
\hline Male patients & $113(60.8)$ & $259(66.1)$ & 0.227 \\
\hline Age, years & $76.0 \pm 9.8$ & $69.2 \pm 12.0$ & $<0.001$ \\
\hline Body mass index & $22.7 \pm 3.2$ & $23.0 \pm 3.4$ & 0.397 \\
\hline Hypertension & $137(73.7)$ & $219(55.9)$ & $<0.001$ \\
\hline Diabetes mellitus & $37(19.9)$ & $70(17.9)$ & 0.568 \\
\hline Dyslipidemia & $35(18.8)$ & $89(22.7)$ & 0.329 \\
\hline Atrial fibrillation & $97(52.2)$ & $148(37.8)$ & 0.001 \\
\hline Liver disease & $8(4.3)$ & $9(2.3)$ & 0.194 \\
\hline Prior ischemic heart disease & $37(19.9)$ & $37(9.4)$ & $<0.001$ \\
\hline Prior ischemic stroke & $39(21.0)$ & $62(15.8)$ & 0.129 \\
\hline Prior use of antithrombotic agents & $92(49.5)$ & $125(31.9)$ & $<0.001$ \\
\hline Systolic blood pressure, $\mathrm{mm} \mathrm{Hg}$ & $150 \pm 20$ & $151 \pm 20$ & 0.613 \\
\hline Diastolic blood pressure, $\mathrm{mm} \mathrm{Hg}$ & $80 \pm 16$ & $83 \pm 15$ & 0.077 \\
\hline \multicolumn{4}{|l|}{ Stroke subtype } \\
\hline Large-artery atherosclerosis & $24(12.9)$ & $65(16.6)$ & \multirow{4}{*}{0.141} \\
\hline Cardioembolism & $128(68.8)$ & $236(60.2)$ & \\
\hline Lacune & $5(2.7)$ & $23(5.9)$ & \\
\hline Other & $29(15.6)$ & $68(17.4)$ & \\
\hline Internal carotid artery occlusion & $29(15.6)$ & $59(15.2)$ & 0.902 \\
\hline Blood glucose, $\mathrm{mmol} / \mathrm{l}$ & $7.68 \pm 2.77$ & $7.61 \pm 2.61$ & 0.787 \\
\hline Hemoglobin A1c, \% & $5.8 \pm 1.0$ & $5.8 \pm 1.1$ & 0.995 \\
\hline Total cholesterol, $\mathrm{mmol} / \mathrm{l}$ & $4.68 \pm 1.07$ & $5.01 \pm 1.01$ & $<0.001$ \\
\hline Triglyceride, $\mathrm{mmol} / \mathrm{l}$ & $1.30 \pm 0.72$ & $1.32 \pm 0.95$ & 0.809 \\
\hline HDL cholesterol, $\mathrm{mmol} / \mathrm{l}$ & $1.27 \pm 0.36$ & $1.38 \pm 0.40$ & 0.003 \\
\hline LDL cholesterol, mmol/l & $2.83 \pm 0.88$ & $3.01 \pm 0.87$ & 0.043 \\
\hline Time to treatment onset, $\min$ & $145(121-167)$ & $146(122-166)$ & 0.991 \\
\hline Admission NIHSS score & $13(7-19)$ & $12(7.25-18)$ & 0.423 \\
\hline
\end{tabular}

Numbers of patients (\%) are shown except otherwise indicated; data are means \pm SD or medians (IQR).

patients belonged to stage $3,15(2.6 \%)$ to stage 4 , and 8 $(1.4 \%)$ to stage 5 . Four patients with stage 5 were on maintenance hemodialysis.

The patients with renal dysfunction were older $(\mathrm{p}<$ $0.001)$ and more commonly had hypertension $(\mathrm{p}<0.001)$, atrial fibrillation $(\mathrm{p}=0.001)$, prior ischemic heart disease $(\mathrm{p}<0.001)$, and prior use of antithrombotic agents $(\mathrm{p}<$ 0.001 ) than patients without renal dysfunction (table 1). Serum total cholesterol ( $\mathrm{p}<0.001)$, HDL cholesterol $(\mathrm{p}=$ $0.003)$, and LDL cholesterol $(p=0.043)$ levels were lower in patients with renal dysfunction than in those without. NIHSS scores were not significantly different between patients with renal dysfunction and those without immediately before [median (interquartile range, IQR); 13 (7$19)$ vs. 12 (7.25-18), $\mathrm{p}=0.423$ ] and $24 \mathrm{~h}$ after IV rt-PA [9 (3-18) vs. 7 (3-15), $\mathrm{p}=0.070$; fig. 1a].

Intravenous rt-PA for Renal Dysfunction in Stroke Patients
Any ICH [51 (27.4\%) vs. 65 patients (16.6\%), p = 0.004] as well as symptomatic ICH within $36 \mathrm{~h}$ from IV rt-PA therapy [15 (8.1\%) vs. 10 patients $(2.6 \%), \mathrm{p}=0.004]$, was more common in the patients with renal dysfunction than in those without. After multivariate logistic regression analysis, renal dysfunction was significantly related to both any $\mathrm{ICH}$ (odds ratio, OR, 1.81, 95\% confidence interval, $\mathrm{CI}, 1.16-2.84, \mathrm{p}=0.009)$ and symptomatic ICH $(2.64,1.10-6.56, \mathrm{p}=0.031$; table 2$)$. When the value of eGFR (a continuous variable) was used instead of eGFR $<60 \mathrm{ml} / \mathrm{min} / 1.73 \mathrm{~m}^{2}$ (a categorical variable) as an indicator of renal dysfunction, it was related to any ICH (OR $0.89,95 \%$ CI $0.80-0.99$ per $10-\mathrm{ml} / \mathrm{min} / 1.73 \mathrm{~m}^{2}$ increase, $\mathrm{p}=0.029)$ but not symptomatic ICH $(0.89,0.73-1.08, \mathrm{p}=$ 0.231).

At 3 months, the patients with renal dysfunction had higher mRS scores than those without [median (IQR); 3

Cerebrovasc Dis 2011;31:123-129 
Fig. 1. Neurological deficits and outcome of patients with and without renal dysfunction. NIHSS score just before and $24 \mathrm{~h}$ after IV rt-PA therapy (a) and mRS score at 3 months (b) in patients with and without renal dysfunction. a Horizontal lines in boxes = Median NIHSS score; boxes = IQR; whiskers = upper and lower 90\% ranges.

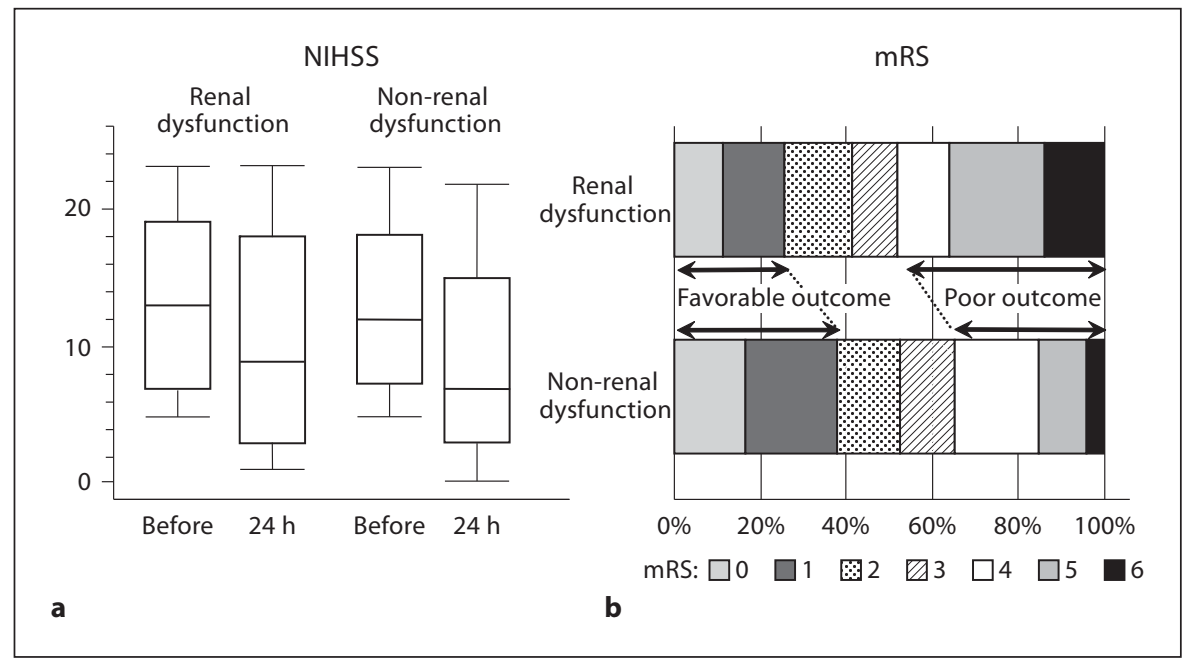

Table 2. Characteristics associated with ICH within $36 \mathrm{~h}$

\begin{tabular}{|c|c|c|c|c|c|c|}
\hline \multirow[t]{2}{*}{ Characteristics } & \multicolumn{3}{|c|}{ Any ICH } & \multicolumn{3}{|c|}{ Symptomatic ICH } \\
\hline & OR & $95 \% \mathrm{CI}$ & $\mathrm{p}$ value & OR & $95 \% \mathrm{CI}$ & $\mathrm{p}$ value \\
\hline Male & 1.12 & $0.71-1.78$ & 0.638 & 1.99 & $0.74-6.32$ & 0.201 \\
\hline Age (per year) & 0.99 & $0.97-1.01$ & 0.423 & 1.00 & $0.96-1.04$ & 0.868 \\
\hline Renal dysfunction $\left(e G F R<60 \mathrm{ml} / \mathrm{min} / 1.73 \mathrm{~m}^{2}\right)$ & 1.81 & $1.16-2.84$ & 0.009 & 2.64 & $1.10-6.56$ & 0.031 \\
\hline Atrial fibrillation & 1.93 & $1.24-3.01$ & 0.004 & - & - & - \\
\hline Liver disease & 1.53 & $0.40-4.79$ & 0.488 & - & - & - \\
\hline Prior use of antithrombotic agents & - & - & - & 4.31 & $1.72-12.06$ & 0.003 \\
\hline Blood glucose (per mmol/l) & 1.06 & $0.98-1.14$ & 0.153 & 1.11 & $0.96-1.26$ & 0.126 \\
\hline Triglyceride (per mmol/l) & - & - & - & 1.00 & $0.99-1.01$ & 0.174 \\
\hline Admission NIHSS score (per point) & 1.03 & $0.99-1.06$ & 0.069 & - & - & - \\
\hline
\end{tabular}

- = The variable was not included after the backward selection procedure.

Table 3. Characteristics associated with outcome at 3 months

\begin{tabular}{|c|c|c|c|c|c|c|c|c|c|}
\hline \multirow[t]{2}{*}{ Characteristics } & \multicolumn{3}{|c|}{ Favorable outcome (mRS $0-1$ ) } & \multicolumn{3}{|c|}{ Poor outcome (mRS 4-6) } & \multicolumn{3}{|c|}{ Death } \\
\hline & OR & $95 \% \mathrm{CI}$ & $\mathrm{p}$ value & OR & $95 \%$ CI & $\mathrm{p}$ value & OR & $95 \% \mathrm{CI}$ & $\mathrm{p}$ value \\
\hline Male & 1.14 & $0.74-1.76$ & 0.545 & 0.84 & $0.55-1.29$ & 0.430 & 0.68 & $0.32-1.48$ & 0.331 \\
\hline Age (per year) & 0.97 & $0.96-0.99$ & 0.005 & 1.04 & $1.02-1.06$ & $<0.001$ & 1.01 & $0.97-1.05$ & 0.718 \\
\hline \multicolumn{10}{|l|}{ Renal dysfunction } \\
\hline$\left(\mathrm{eGFR}<60 \mathrm{ml} / \mathrm{min} / 1.73 \mathrm{~m}^{2}\right)$ & 0.70 & $0.44-1.09$ & 0.114 & 1.55 & $1.01-2.38$ & 0.046 & 2.94 & $1.38-6.42$ & 0.006 \\
\hline Prior ischemic heart disease & - & - & - & - & - & - & 4.33 & $1.84-10.05$ & $<0.001$ \\
\hline Internal carotid artery occlusion & 0.24 & $0.10-0.51$ & $<0.001$ & 6.07 & $3.38-11.39$ & $<0.001$ & 4.32 & $2.00-9.36$ & $<0.001$ \\
\hline Blood glucose (per mmol/l) & 0.91 & $0.84-0.99$ & 0.024 & 1.08 & $1.01-1.17$ & 0.033 & 1.17 & $1.04-1.31$ & 0.007 \\
\hline Admission NIHSS score (per point) & 0.91 & $0.88-0.94$ & $<0.001$ & 1.11 & $1.08-1.15$ & $<0.001$ & 1.09 & $1.04-1.15$ & $<0.001$ \\
\hline
\end{tabular}

$-=$ The variable was not included after the backward selection procedure. For favorable outcome analysis, patients with premorbid mRS score $2-3$ were excluded. 
(1-5) vs. 2 (1-4), p < 0.001; fig. 1b]. Twenty-five patients (13.4\%) with renal dysfunction had died; of these, 5 died of stroke, 6 of heart disease (4 heart failure, 1 myocardial infarction, and 1 infectious endocarditis), 6 of severe infection (3 sepsis and 3 pneumonia), and 8 of unknown causes. In contrast, 15 patients $(3.8 \%, p<0.001)$ without renal dysfunction had died; of these, 9 died of stroke, 2 of pneumonia, and 4 of unknown causes. Similarly, favorable outcome was less common [48 (25.8\%) vs. 149 patients (38.0\%), $\mathrm{p}=0.004]$, and poor outcome was more common [89 (47.9\%) vs. 136 patients (34.7\%), $\mathrm{p}=0.003$ ] in patients with renal dysfunction than in those without. After multivariate logistic regression analysis, renal dysfunction was significantly related to poor outcome (OR 1.55, 95\% CI 1.01-2.38, $\mathrm{p}=0.046)$ and mortality (OR 2.94, 95\% CI $1.38-6.42, \mathrm{p}=0.006)$, although it was not related to favorable outcome (OR 0.70, 95\% CI 0.44-1.09, p = 0.114; table 3). When the value of eGFR was used instead, it was significantly related to mortality (OR $0.81,95 \%$ CI $0.67-$ 0.96 per $10-\mathrm{ml} / \mathrm{min} / 1.73 \mathrm{~m}^{2}$ increase, $\mathrm{p}=0.020$ ), but not to favorable outcome (OR 1.09, 95\% CI 0.99-1.20, p = 0.081) or poor outcome (OR $0.95,95 \%$ CI $0.86-1.04, \mathrm{p}=0.268$ ).

\section{Discussion}

In this observational study, we determined the influence of renal dysfunction on early ICH and the long-term outcome of ischemic stroke patients receiving IV rt-PA therapy. The major finding was that renal dysfunction, defined as reduced eGFR $\left(<60 \mathrm{ml} / \mathrm{min} / 1.73 \mathrm{~m}^{2}\right)$, which was calculated using the admission creatinine level, was related to any ICH and symptomatic ICH within $36 \mathrm{~h}$, as well as poor outcome (mRS 4-6) and death at 3 months, although it was not related to favorable outcome (mRS 0-1).

According to the result of the largest postmarketing surveillance on rt-PA, the Safe Implementation of Thrombolysis in Stroke-Monitoring Study [21], advanced age, body weight, atrial fibrillation, high systolic blood pressure, hyperglycemia, admission NIHSS score, and current infarction on baseline imaging scans were associated with symptomatic ICH. In addition, advanced age, male sex, use of antiplatelet agents other than aspirin, congestive heart failure, higher diastolic blood pressure, hyperglycemia, higher NIHSS score, current infarction, and premorbid dependency were related to death at 3 months. Similar results have been reported in several other studies [22-26]. However, these studies did not assess renal dysfunction as a potential factor affecting stroke outcome. The present study is unique in that renal dysfunction was included as a potential factor and was proven to be associated with patient outcome after rt-PA.

Alteplase is metabolized by the liver, and liver function affects the half-life of alteplase [27]. In this study, liver disease was not associated with stroke outcome. In contrast, renal dysfunction might not prolong the halflife of alteplase. For example, the plasma concentrationtime profile of alteplase was not altered after bilateral nephrectomy in rat models [28].

Renal dysfunction is a bystander of stroke, since it is associated with traditional vascular risk factors, including aging, hypertension, diabetes mellitus, dyslipidemia, and smoking [29]. In addition, renal dysfunction is now known to be an independent predictor for stroke $[1,2,5$, $30,31]$, partly via nontraditional vascular risk factors, e.g. inflammatory factors, and homocysteinemia. However, the effect of these nontraditional risk factors on stroke outcome has not been clarified, in particular after rt-PA. In patients with acute stroke not receiving IV rt-PA, albuminuria was independently associated with hemorrhagic transformation [32]. Since ICH is a major cause of poor outcome for thrombolysed patients, renal dysfunction may affect chronic outcome after rt-PA via increasing ICH risk. Moreover, renal dysfunction might impair endothelial release of t-PA [33], and increase plasminogen activator inhibitor-1 activity [34] and plasma levels of lipoprotein(a) [35]; these abnormalities might obstruct the reperfusion phenomenon and worsen stroke outcome after IV rt-PA.

An interesting finding regarding the patients who died was that indirect death other than stroke was common as the cause of death for patients with renal dysfunction, though direct stroke death accounted for most of the causes of death for patients without renal dysfunction. This finding suggests that patients with renal dysfunction often had heart problems and susceptibility to infection, developed dependency and died due to non-stroke complications.

Certain limitations need to be considered prior to interpretation of the present results. First, patients who did not receive IV rt-PA were not included in this study. Thus, the influence of renal dysfunction on stroke outcome could not be compared between patients who were treated with rt-PA and those who were not. Second, renal dysfunction was correlated with older age, hypertension, atrial fibrillation, prior ischemic heart disease, and prior use of antithrombotic agents, and this multicolineality may inflate the variances of the parameter estimates. Thus, the present association of renal dysfunction with outcome measures after multivariate analyses may be 
overestimated to some extent. Third, eGFR was not measured prior to stroke onset, and therefore eGFR may have been affected by stroke. Fourth, eGFR was calculated using admission creatinine levels, which may have been impaired by acute stroke effects. Repeated assessment in the chronic stroke stage is needed to ascertain that the present patients with reduced eGFR have chronic kidney disease. Fifth, urinary albumin was not measured. Generally, urinary albumin increases during acute ischemic stroke [36]. Finally, the present results based on low-dose rt-PA therapy $(0.6 \mathrm{mg} / \mathrm{kg})$ may not be applicable to the regular dose therapy $(0.9 \mathrm{mg} / \mathrm{kg})$.

In conclusion, reduced eGFR based on the admission creatinine level was predictive of an unfavorable outcome after IV rt-PA in acute stroke patients. In patients with renal dysfunction, additional therapeutic strategies to improve the efficacy of rt-PA are needed.

\section{Disclosure Statement}

M.K. received a grant from the Japan Cardiovascular Research Foundation (The Bayer Scholarship for Cardiovascular Research). J.N. received honoraria from Mitsubishi Tanabe Pharma, Kyowa Hakko Kirin, and Lundbeck. Y.O. received a honorarium from Mitsubishi Tanabe Pharma and a consulting fee from Lundbeck. K.M. received research support from the Ministry of Health, Labour and Welfare, Japan, research grants for cardiovascular diseases, grant-in-aid, the Foundation for Biomedical Research and Innovation, Mitsubishi Tanabe Pharma Corporation, and Kyowa Hakko Kirin Pharma, Inc., Hitachi Medical Corporation. K.T. received research support from grants-in-aid (H20-Junknaki-Ippan-019) from the Ministry of Health, Labour and Welfare, Japan.

\section{References}

1 Yuyun MF, Khaw KT, Luben R, Welch A, Bingham S, Day NE, Wareham NJ: Microalbuminuria and stroke in a British population: the European Prospective Investigation into Cancer in Norfolk (EPIC-Norfolk) population study. J Intern Med 2004;255:247256.

2 Ninomiya T, Kiyohara Y, Kubo M, Tanizaki Y, Doi Y, Okubo K, Wakugawa Y, Hata J, Oishi Y, Shikata K, Yonemoto K, Hirakata H, Iida M: Chronic kidney disease and cardiovascular disease in a general Japanese population: the Hisayama study. Kidney Int 2005; 68:228-236.

- 3 Guerrero-Romero F, Rodriguez-Moran M: Proteinuria is an independent risk factor for ischemic stroke in non-insulin-dependent diabetes mellitus. Stroke 1999;30:1787-1791.

-4 De Leeuw PW, Thijs L, Birkenhager WH, Voyaki SM, Efstratopoulos AD, Fagard RH, Leonetti G, Nachev C, Petrie JC, Rodicio JL, Rosenfeld JJ, Sarti C, Staessen JA: Prognostic significance of renal function in elderly patients with isolated systolic hypertension: results from the Syst-Eur trial. J Am Soc Nephrol 2002; 13:2213-2222.

$\checkmark 5$ Koren-Morag N, Goldbourt U, Tanne D: Renal dysfunction and risk of ischemic stroke or TIA in patients with cardiovascular disease. Neurology 2006;67:224-228.

6 Klausen KP, Scharling H, Jensen JS: Very low level of microalbuminuria is associated with increased risk of death in subjects with cardiovascular or cerebrovascular diseases. J Intern Med 2006;260:231-237.
7 MacWalter RS, Wong SY, Wong KY, Stewart G, Fraser CG, Fraser HW, Ersoy Y, Ogston SA, Chen R: Does renal dysfunction predict mortality after acute stroke? A 7-year followup study. Stroke 2002;33:1630-1635.

8 Yahalom G, Schwartz R, Schwammenthal Y, Merzeliak O, Toashi M, Orion D, Sela BA, Tanne D: Chronic kidney disease and clinical outcome in patients with acute stroke. Stroke 2009;40:1296-1303.

-9 Tsagalis G, Akrivos T, Alevizaki M, Manios E, Stamatellopoulos K, Laggouranis A, Vemmos KN: Renal dysfunction in acute stroke: an independent predictor of long-term all combined vascular events and overall mortality. Nephrol Dial Transplant 2009;24:194200.

10 Lyrer PA, Fluri F, Gisler D, Papa S, Hatz F, Engelter ST: Renal function and outcome among stroke patients treated with IV thrombolysis. Neurology 2008;71:15481550.

11 Toyoda K, Koga M, Naganuma M, Shiokawa Y, Nakagawara J, Furui E, Kimura K, Yamagami $\mathrm{H}$, Okada $\mathrm{Y}$, Hasegawa $\mathrm{Y}$, Kario $\mathrm{K}$, Okuda S, Nishiyama K, Minematsu K: Stroke Acute Management with Urgent Risk-factor Assessment and Improvement (SAMURAI) Study Investigators. Routine use of intravenous low-dose rt-PA in Japanese patients: general outcomes and prognostic factors from the SAMURAI register. Stroke 2009; 40:3591-3595
12 Nezu T, Koga M, Kimura K, Shiokawa Y, Nakagawara J, Furui E, Yamagami H, Okada Y, Hasegawa Y, Kario K, Okuda S, Nishiyama K, Naganuma M, Minematsu K, Toyoda K: Pretreatment ASPECTS on DWI predicts 3-month outcome following rt-PA: SAMURAI rt-PA Registry. Neurology 2010;75:555561.

13 Yamaguchi T, Mori E, Minematsu K, Nakagawara J, Hashi K, Saito I, Shinohara Y, Japan Alteplase Clinical Trial (J-ACT) Group: Alteplase at $0.6 \mathrm{mg} / \mathrm{kg}$ for acute ischemic stroke within 3 hours of onset: Japan Alteplase Clinical Trial (J-ACT). Stroke 2006; 37:1810-1815.

-14 Adams HP Jr, Bendixen BH, Kappelle LJ, Biller J, Love BB, Gordon DL, Marsh EE 3rd: Classification of subtype of acute ischemic stroke. Definitions for use in a multicenter clinical trial. TOAST. Trial of Org 10172 in Acute Stroke Treatment. Stroke 1993;24:3541.

15 Matsuo S, Imai E, Horio M, Yasuda Y, Tomita K, Nitta K, Yamagata K, Tomino Y, Yokoyama $\mathrm{H}$, Hishida $\mathrm{A}$, on behalf of the collaborators developing the Japanese equation for estimated GFR: Revised equations for estimated GFR from serum creatinine in Japan. Am J Kidney Dis 2009;53:982-992.

16 National Kidney Foundation: K/DOQI clinical practice guidelines for chronic kidney disease: evaluation, classification, and stratification. Am J Kidney Dis 2002;39:S1-S266.

17 The National Institute of Neurological Disorders and Stroke rt-PA Stroke Study Group: Tissue plasminogen activator for acute ischemic stroke. N Engl J Med 1995;333:15811587. 
-18 Kwiatkowski TG, Libman RB, Frankel M, Tilley BC, Morgenstern LB, Lu M, Broderick JP, Lewandowski CA, Marler JR, Levine SR, Brott T: Effects of tissue plasminogen activator for acute ischemic stroke at one year. $\mathrm{Na}$ tional Institute of Neurological Disorders and Stroke Recombinant Tissue Plasminogen Activator Stroke Study Group. N Engl J Med 1999;340:1781-1787.

-19 The NINDS t-PA Stroke Study Group: Generalized efficacy of t-PA for acute stroke. Subgroup analysis of the NINDS t-PA Stroke Trial. Stroke 1997;28:2119-2125.

-20 Frankel MR, Morgenstern LB, Kwiatkowski T, Lu M, Tilley BC, Broderick JP, Libman R, Levine SR, Brott T: Predicting prognosis after stroke: a placebo group analysis from the National Institute of Neurological Disorders and Stroke rt-PA Stroke Trial. Neurology 2000;55:952-959.

-21 Wahlgren N, Ahmed N, Eriksson N, Aichner F, Bluhmki E, Dávalos A, Erilä T, Ford GA, Grond M, Hacke W, Hennerici MG, Kaste M, Köhrmann M, Larrue V, Lees KR, Machnig T, Roine RO, Toni D, Vanhooren G, Safe Implementation of Thrombolysis in StrokeMOnitoring STudy Investigators: Multivariable analysis of outcome predictors and adjustment of main outcome results to baseline data profile in randomized controlled trials: Safe Implementation of Thrombolysis in Stroke-MOnitoring STudy (SITS-MOST). Stroke 2008;39:3316-3322.

-22 Demchuk AM, Morgenstern LB, Krieger DW, Linda Chi T, Hu W, Wein TH, Hardy RJ, Grotta JC, Buchan AM: Serum glucose level and diabetes predict tissue plasminogen activator-related intracerebral hemorrhage in acute ischemic stroke. Stroke 1999;30:34-39.
23 Kidwell CS, Saver JL, Carneado J, Sayre J, Starkman S, Duckwiler G, Gobin YP, Jahan R, Vespa P, Villablanca JP, Liebeskind DS Vinuela F: Predictors of hemorrhagic transformation in patients receiving intra-arterial thrombolysis. Stroke 2002;33:717-724.

24 Larrue V, von Kummer RR, Müller A, Bluhmki E: Risk factors for severe hemorrhagic transformation in ischemic stroke patients treated with recombinant tissue plasminogen activator: a secondary analysis of the European-Australasian Acute Stroke Study (ECASS II). Stroke 2001;32 438-441.

25 Counsell C, Dennis M: Systematic review of prognostic models in patients with acute stroke. Cerebrovasc Dis 2001;12:159-170.

26 Tanne D, Kasner SE, Demchuk AM, KorenMorag N, Hanson S, Grond M, Levine SR: Markers of increased risk of intracerebral hemorrhage after intravenous recombinant tissue plasminogen activator therapy for acute ischemic stroke in clinical practice: the Multicenter rt-PA Stroke Survey. Circulation 2002;105:1679-1685.

27 Korninger C, Stassen JM, Collen D: Turnover of human extrinsic (tissue-type) plasminogen activator in rabbits. Thromb Haemost 1981;46:658-661.

28 Martin U, Sponer G, Strein K: Influence of hepatic and renal failure on pharmacokinetic properties of the novel recombinant plasminogen activator BM 06.022 in rats. Drug Metab Dispos 1993;21:236-241.

29 Uhlig K, Levey AS, Sarnak MJ: Traditional cardiac risk factors in individuals with chronic kidney disease. Semin Dial 2003; 16: 118-127.

30 Go AS, Chertow GM, Fan D, McCulloch CE, Hsu CY: Chronic kidney disease and the risks of death, cardiovascular events, and hospitalization. N Engl J Med 2004;351: 1296-1305.
31 McCullough PA, Li S, Jurkovitz CT, Stevens LA, Wang C, Collins AJ, Chen SC, Norris KC, McFarlane SI, Johnson B, Shlipak MG, Obialo CI, Brown WW, Vassalotti JA, Whaley-Connell AT, Kidney Early Evaluation Program Investigators: CKD and cardiovascular disease in screened high-risk volunteer and general populations: the Kidney Early Evaluation Program (KEEP) and National Health and Nutrition Examination Survey (NHANES) 1999-2004. Am J Kidney Dis 2008;51:S38-S45.

>32 Rodriguez-Yanez M, Castellanos M, Blanco M, Millan M, Nombela F, Sobrino T, Lizasoain I, Leira R, Serena J, Davalos A, Castillo $\mathrm{J}$ : Micro- and macroalbuminuria predict hemorrhagic transformation in acute ischemic stroke. Neurology 2006;67:1172-1177.

33 Hrafnkelsdottir T, Ottosson P, Gudnason T, Samuelsson O, Jern S: Impaired endothelial release of tissue-type plasminogen activator in patients with chronic kidney disease and hypertension. Hypertension 2004;44:300304.

-34 Kamgar M, Nobakhthaghighi N, Shamshirsaz AA, Estacio RO, McFann KK, Schrier RW: Impaired fibrinolytic activity in type II diabetes: correlation with urinary albumin excretion and progression of renal disease. Kidney Int 2006;69:1899-1903.

- 35 Kronenberg F, Utermann G, Dieplinger H: Lipoprotein(a) in renal disease. Am J Kidney Dis 1996;27:1-25.

-36 Slowik A, Turaj W, Iskra T, Strojny J, Szczudlik A: Microalbuminuria in nondiabetic patients with acute ischemic stroke: prevalence, clinical correlates, and prognostic significance. Cerebrovasc Dis 2002;14:1521 . 